\title{
HLA antigens in psoriatic arthritis subtypes of a Spanish population
}

\author{
C López-Larrea, J C Torre Alonso, A Rodriguez Perez, Eliecer Coto
}

\begin{abstract}
HLA-A, B, and C antigens were studied in 104 Spanish patients with psoriatic arthritis. Different clinical features were evaluated and the patients divided into disease subsets. HLAB17, B27, B16, and Cw6 were the most common haplotypes in the total group. The HLA-B17/Cw6 haplotype was increased in patients with oligoarthritis. The increase of antigen B17 correlated with oligoarthritis and spondarthritis, whereas Cw6 was more significant in oligoarthritis. The prevalence of the B27/Cw1 haplotype was greater in association with spondarthritis and was probably related to the B27.5 subtype linked to Cw1. A significant negative association between the $B 44 / C w 5$ haplotype and psoriatic arthritis was found. The existence of several haplotypic factors in the different subsets is discussed. Lack of one or more HLA factors is thought to be responsible for the different clinical forms of psoriatic arthritis.
\end{abstract}

Several studies have found an association between susceptibility of psoriatic arthritis and HLA-B17, B13, B27, B37 antigens. ${ }^{1-4}$ This antigen association seems to be secondary to the stronger Cw6 association. ${ }^{5}$ Studies of different families have shown that the HLA genetic factor plays a major part in the development of psoriatic arthritis, ${ }^{67}$ but its mode of inheritance is at present unclear. ${ }^{8}$ Different HLA class I antigens may be linked to psoriatic arthritis susceptibility in different populations, but the relation between HLA antigens and clinical subsets of psoriatic arthritis has not been sufficiently investigated. The aim of this study was to map susceptibility genes within the HLA in a large sample of Spanish subjects with psoriatic arthritis using available HLA markers, and to correlate the prevalence of these markers with subsets of different clinical features.

Inmunologia, Hospital NS Covadonga, Oviedo C López-Larrea E Coto

Reumatologia, Hospital NS Covadonga, Oviedo, Spain

J C Torre Alonso

A Rodriguez Perez

Correspondence to: Dr C López-Larrea Inmunologia, Hospital NS Covadonga, c/Villamil $s / n$, 33006 Oviedo, Spain.

Accepted for publication 10 July 1989

\section{Patients and methods}

\section{POPULATION SAMPLE}

HLA-A, B, and C antigens were studied in 104 unrelated patients with psoriatic arthritis. The diagnostic criteria used were those established by Moll and Wright. ${ }^{7}$ Healthy volunteers (109) from a sample of the Spanish population served as controls. Several clinical features were evaluated and the patients divided into disease subsets: 36 had oligoarthritis, 30 polyarthritis, and 28 spondarthritis. Moreover, five had arthritis mutilans and five the distal form with involvement of the distal interphalangeal joint.
HLA TYPING

HLA-A, B, and C typing was carried out by a standard microlymphocytotoxicity technique on peripheral lymphocytes. ${ }^{9}$ Local and 9th HLA Workshop antisera were used.

\section{STATISTICAL ANALYSIS}

Data were analysed by a computer program. When the antigen prevalences deviated significantly from those of normal subjects the corresponding $p$ values were multiplied by the number of antigens, which were only considered when there were more than 20 . The $\chi^{2}$ test was used to compare the prevalences of HLA antigens, and Yates's correction was applied. Relative risk (RR) was also calculated according to Svejgaard et al. ${ }^{10}$

\section{Results}

Table 1 lists the prevalences of HLA-A, B, and $\mathrm{C}$ antigens in 104 patients with psoriatic arthritis and in the controls. Significant association was found between psoriatic arthritis and HLAB17, B27, B16 (table 1), which confirmed previous results. ${ }^{2}{ }^{3}$ HLA-B17, which is in

Table 1: Prevalence of relevant HLA antigens in 104 northern Spanish patients and in controls

\begin{tabular}{|c|c|c|c|}
\hline Antigens & $\begin{array}{l}\text { Patients } \\
\text { with } \\
\text { psoriatic } \\
\text { arthritis } \\
(n=104)\end{array}$ & $\begin{array}{l}\text { Controls } \\
(n=109)\end{array}$ & $\begin{array}{l}\text { Relative } \\
\text { risk } \\
\left(\chi^{2}\right)\end{array}$ \\
\hline $\begin{array}{l}\text { B17 } \\
\text { B27 } \\
\text { B16 } \\
\text { B44 } \\
\text { Cw4 } \\
\text { Cw5 } \\
\text { Cw6 } \\
\text { B44/Cw5 }\end{array}$ & $\begin{array}{r}19 \cdot 2 \\
22 \cdot 1 \\
5 \cdot 2 \\
14 \cdot 4 \\
11 \cdot 5 \\
1 \cdot 2 \\
20 \cdot 1 \\
1 \cdot 1\end{array}$ & $\begin{array}{r}4 \cdot 6 \\
3 \cdot 7 \\
2 \cdot 3 \\
29 \cdot 4 \\
22 \cdot 2 \\
12 \cdot 8 \\
3 \cdot 7 \\
9 \cdot 3\end{array}$ & $\begin{array}{l}4.9(8.0)^{+} \\
7.4(16.3)^{+\ldots+} \\
4.4(4.1)^{+} \\
0.4(6.9)^{+} \\
0.4(4.1)^{+} \\
0.1(11 \cdot 4)^{+k} \\
6.2(12.8)^{+k} \\
0.1(7.3)^{+}\end{array}$ \\
\hline
\end{tabular}

${ }^{*} \mathrm{p}<0.05 ;{ }^{* *} \mathrm{p}<0.01 ;{ }^{* * *} \mathrm{p}<0.005$.

Table 2: HLA antigens in psoriatic arthritis subsets. Values are shown as the percentage of patients in each subset possessing a particular antigen with relative risk in parentheses

\begin{tabular}{|c|c|c|c|}
\hline Antigen & $\begin{array}{l}\text { Oligoarthritis } \\
(n=36)\end{array}$ & $\begin{array}{l}\text { Polyarthritis } \\
(n=30)\end{array}$ & $\begin{array}{l}\text { Spondarthritis } \\
(n=28)\end{array}$ \\
\hline $\begin{array}{l}\text { B13 } \\
\text { B7 } \\
\text { B16 } \\
\text { B37 } \\
\text { B17 } \\
\text { B27 } \\
\text { Cw1 } \\
\text { Cw6 } \\
\text { B27/Cw1 } \\
\text { B17/Cw6 }\end{array}$ & $\begin{array}{ll}14 & (4 \cdot 6)^{*} \\
13 \cdot 9 & (0 \cdot 2) \\
3 & (1 \cdot 7) \\
\frac{1}{22} \cdot 2 & (5 \cdot 9)^{*} \\
11 \cdot 1 & (4 \cdot 0) \\
\frac{1}{27} \cdot 8 & (10)^{* * *} \\
\frac{6}{6} & (8 \cdot 2)^{* *}\end{array}$ & $\begin{array}{l}\overline{30}(3 \cdot 4) \\
\overline{10}(1 \cdot 2) \\
\overline{10}(2 \cdot 9) \\
\overline{17}(5 \cdot 2)^{*} \\
=\end{array}$ & $\begin{array}{l}\overline{-} \\
\frac{7}{7}(3.9) \\
\frac{25}{54}(6.6)^{*} \\
21(5 \cdot 4)^{* * \ldots} \\
\frac{11}{11}(13 \cdot 8)^{* * *} \\
-\end{array}$ \\
\hline
\end{tabular}


linkage disequilibrium with $\mathrm{Cw} 6,{ }^{2-4}$ was significantly increased $(19.2 v 4.6 ; \mathrm{p}<0.05)$. Additionally, B44, Cw4, and Cw5 were decreased, though not significantly, in psoriatic arthritis. When different groups were analysed (table 2) the antigen B17 was relevant in both oligoarthritis $(R R=5.9 ; p<0.05)$ and spondarthritis $(R R=6.6 ; p<0.05)$. The antigen Cw6 had an important relative risk only in oligoarthritis $(R R=10 ; p<0.01)$; it was absent in spondarthritis. In contrast, B27 was more prevalent in patients with spondarthritis $(R R=$ 38.8; $\mathrm{p}<0.005)$. The increase in the $\mathrm{Cwl}$ antigen in spondarthritis was probably secondary to the noted $B 27$ association $(R R=5.4 ; p<0.05)$. Correlation was found between B7, B37 and the polyarticular form (table 2).

\section{Discussion}

Several studies have sought an association between susceptibility to psoriatic arthritis and the HLA antigens. Psoriatic arthritis has been reported to be associated with HLA-B17, B37, $B 13$, and Cw6..$^{2-4}$ Our study was performed in a large group of Spanish patients with psoriatic arthritis. The results are in agreement with those found by other authors in Caucasoids. ${ }^{2} 311$ The B17 antigen is related to oligoarthritis and spondarthritis subsets in the Spanish population. Cw6 is more strongly associated with oligoarthritis than with polyarthritis. These findings have not been described previously. It has been noted, however, that the B17/Cw6 haplotype in Caucasoids is weakly maintained in the Spanish population. ${ }^{9}$ These facts support the idea that $\mathrm{B} 17$ and $\mathrm{Cw} 6$ might act as independent genetic factors of susceptibility, resulting in different clinical manifestations. Nevertheless, the relative risk in oligoarthritis is higher for patients with B17/Cw6 than for those with B17 alone. Several closely linked factors promoting susceptibility to psoriatic arthritis may exist within an HLA haplotype (B17/Cw6). All may be necessary for the occurrence of oligoarthritis. Lack of one or more factors (B17 in polyarthritis, Cw6 in spondarthritis) might lead to the different clinical forms. In patients tested B27 is increased and correlates with a spondarthritis subset. The Cwl association found with psoriatic arthritis is secondary to B27. Several studies show the existence of at least seven B27 subtypes. ${ }^{12}{ }^{13}$ An interesting question is whether the association of B27 with psoriatic arthritis involves just one B27 subtype. HLA-B27 is in linkage dis- equilibrium with $\mathrm{Cw} 1$ and $\mathrm{Cw} 2$ in Caucasoids. ${ }^{13}$ The HLA-B27.5 subtype is in linkage disequilibrium with both $\mathrm{Cw} 1$ and $\mathrm{Cw} 2$. On the other hand, B27.2 is almost exclusively linked to $\mathrm{Cw} 2$. The results (increase of $\mathrm{B} 27 / \mathrm{Cwl}$ in spondarthritis) suggest that B27.5 is probably associated with spondarthritis in Spanish patients; analysis by isoelectric focusing is needed for confirmation of this. This result contrasts with the $\mathrm{Cw} 2$ increase described by Gladman et al, which is probably secondarily associated with both B27.2 and B27.5 subtypes in American patients. ${ }^{3}$ The association of B37 and B13 with psoriatic arthritis seems to be secondary to the stronger Cw6 association. The negative association of the $\mathrm{B} 44 / \mathrm{Cw} 5$ haplotype has not been previously reported and may have a protective role against the development of psoriatic arthritis.

These findings further support the hypothesis that psoriatic arthritis is a heterogeneous disorder. Several closely linked psoriatic arthritis susceptibility factors may exist within an HLA haplotype. Their presence may be necessary for the development of psoriatic arthritis. Absence of one or several HLA susceptibility factors may lead to the development of different clinical forms.

1 Lambert J R, Wright V, Rajah S M, Moll J M H. Histocompatibility antigens in psoriatic arthritis. Ann Rheum Dis 1976: 35: 526-30.

2 McKendry R J, Sengar D P, DesGroseilliers J P, Dunne J B. Frequency of $\mathrm{HLA}$ antigens in patients with psoriasis or Frequency of HLA antigens in patients with psoriasis
psoriatic arthritis. Can Med Assoc $\mathcal{Z} 1984 ; 130: 411-5$.

3 Gsoriatic arthritis. Can Med Assoc f 1984; 130: Mervart H. HLA antigens in psoriatic arthritis. $\mathcal{J}$ Rheumatol 1986; 13: HL6-92.

4 McHugh N J, Laurent M R, Treadwell B L, Tweed J M, Dagger J. Psoriatic arthritis: clinical subgroups and histocompatibility antigens. Ann Rheum Dis 1987; 46: 184-7.

5 Tillikainen A, Lassus A, Karvonen J, Vartainen P, Julin M Psoriasis and HLA-Cw6. Br $\mathcal{F}$ Dermatol 1980; 102: 179-84.

6 Gladman D D. The role of immunological factors in the pathogenesis and etiology of psoriatic arthritis. In: Gerber pathogenesis and etiology of psoriatic arthritis. In: Gerber L H, Espinoza L R, eds. Psor

7 Moll J M H,Wright V. Psoriatic arthritis. Semin Arthritis Rheum 1973; 3: 55-78.

8 Espinoza L R, Vasey F B, Gailord S W, et al. Histocompatibility typing in the seronegative spondyloarthropathies: survey. Semin Arthritis Rheum 1982; 11: 375-81.

9 Arnaiz-Villena A, Rodriguez de Córdoba S, Vela F, Pascual $J$ C, Cervero J, Bootello A. HLA antigens in a sample of the Spanish population: common features among Spanish Basques and Sardinians. Hum Genet 1981; 58: 344-8.

10 Svejgaard A, Jersild C, Staub-Nielsen L, Bodmer W F. HLA antigens disease. Statistical and genetic considerations. Tissue Antigens 1974; 4: 95-9.

11 Marcusson J A, Johannesson A, Möller E. HLA-A, B, C and DR antigens in psoriasis. Tissue Antigens 1981; 17: 525-9.

12 Choo S Y, Antonelli P, Nisperos B, Nepom G T, Hansen J A. Six variants of HLA-B27 identified by isoelectric focusing.

13 Breur-Vriesendorp B S, Waal L P, Ivanyi P. Different linkage disequilibria of HLA-B27 subtypes and HLA-C locus alleles. Tissue Antigens 1988; 32: 74-7. 